\title{
COMO SER FELIZ EM MEIO AO PORTUNHOL QUE SE PRODUZ NA SALA DE AULA DE ESPANHOL: POR UMA PEDAGOGIA TRANSLÍNGUE
}

\author{
HOW TO BE HAPPY AMID THE PORTUÑOL PRODUCED \\ IN THE SPANISH LANGUAGE CLASSROOM: TOWARDS A \\ TRANSLANGUAGING PEDAGOGY
}

\section{Fernando Zolin-Vesz}

\section{RESUMO}

Este artigo se contrapõe à perspectiva que associa o portunhol à noção de interlíngua, que conduz ao erro e à insuficiência do aprendiz que não progride em direção ao domínio proficiente da língua espanhola. Por meio de conceitos oriundos da Sociolinguística e dos estudos do discurso, busca-se construir uma concepção do portunhol que se produz na sala de aula de espanhol como translíngua, como produto de uma epistemologia de fronteira. Dessa forma, propõe-se para o ensino de espanhol uma pedagogia translíngue, que se pauta no movimento entre as fronteiras linguísticas do português e do espanhol, no movimento que o aprendiz faz, como falante de língua portuguesa, em direção à criação de sentidos na sala de aula de espanhol.

Palavras-chave: portunhol; translíngua; pedagogia translíngue.

\section{ABSTRACT}

This article challenges the perspective which links portuñol to the concept of interlanguage, leading language learners both to errors and to failure, as well as causing them not to progressing toward a proficiency in Spanish. From the standpoint of Sociolinguistics and discourse studies, the aim is to launch a conception of the portunol produced in the Spanish language classroom as translanguaging, a product of a border epistemology. Thus, it is proposed a translanguaging pedagogy for Spanish teaching grounded on the movement between the linguistic borders of Portuguese and Spanish, as well as on the movement that the learner produces as a Portuguese speaker in order to create meanings in the Spanish language classroom.

Keywords: portuñol; translanguaging; translanguaging pedagogy.

\footnotetext{
* IFMT, Cuiabá (MT), Brasil. fernando vesz@hotmail.com
} 


\title{
INTRODUÇÃO
}

No âmbito do ensino de espanhol no Brasil, o portunhol é caracterizado como uma "mistura" entre o português e o espanhol, geralmente associada ao domínio insuficiente de um sujeito que se encontra em processo de aquisição da língua espanhola. Dessa forma, falar portunhol na sala de aula significaria "uma maneira errada" ou "falar mal" espanhol, referindo-se às produções linguísticas realizadas pelos aprendizes durante o processo de aprendizagem da língua espanhola (REIS, 2010; MOTA, 2012).

Segundo essa perspectiva, dessa "mistura" entre o português e o espanhol nasce uma interlíngua, resultado das interferências do português no aprendizado da língua espanhola. Considerando que a aquisição de uma língua estrangeira se dá pela sucessão de estágios até atingir um resultado final, essa interlíngua, partindo do português em direção ao espanhol, seria um desses estágios que, nessa linha, deveria ser transitório. Daí o portunhol ser considerado muitas vezes de forma negativa, pois, além de ser associado ao erro e à insuficiência, também sugere a não progressão do aprendiz em direção ao domínio proficiente da língua espanhola (MOTA, 2012). Como bem resume e questiona Sato (2010):

\begin{abstract}
en su acepción más primaria apunta a la noción de error, de mezcla, de interlingua que hay que borrar: no bables portuñol, estudia español para no caer en el portuñol, al principio te lo perdonan y queda simpático pero después no. ¿Qué es: el cuco con que los profesores amenazan, la prueba de que existe una pureza de las lenguas? ¿Su denuncia apuntala la importancia y demanda de una educación legal y formal que contemple la enseñanza correcta de lenguas? (SATO, 2010, s/n)
\end{abstract}

Em oposição a essa perspectiva, ou seja, o portunhol associado à noção de "interlíngua", de "mistura do português com palavras da língua espanhola", que deve ser apagado, pois conduz ao erro e à insuficiência do aprendiz, que não progride em direção ao domínio proficiente da língua espanhola, busco construir, neste artigo, por meio de conceitos oriundos da sociolinguística e dos estudos do discurso, como translíngua ${ }^{1}$ (GARCÍA; SYNVAL, 2011; GARCÍA ; FLORES; WOODLEY, 2012), epistemologia de fronteira (MOITA LOPES, 2008) e pedagogia translíngue ${ }^{2}$ (GARCÍA; FLORES; WOODLEY, 2012), uma concepção menos negativa do portunhol que se produz na sala de aula de espanhol.

Convém salientar, portanto, que não me refiro aqui ao portunhol como manifestação literária, ou àquele encontrado na mídia, nem a uma língua de fronteira,

\footnotetext{
1 Tradução minha, do termo translanguaging.

2 Tradução minha, do termo translanguaging pedagogies.
} 
como é o caso do fronterizo entre o Brasil e o Uruguai, ou ainda ao portunhol ibérico, na fronteira entre Portugal e Espanha (sobre essa gama de fenômenos linguísticos identificados como portunhol, ver LIPSKI, 2006; REIS, 2010; MOTA, 2012). Refiro-me àquela forma rejeitada pelo ensino de espanhol, que parece contribuir apenas para reproduzir e perpetuar concepções monolíngues do que significa ensinar/aprender línguas.

\section{MONOLINGUISMO E ENSINO DE LÍNGUAS}

Para apresentar uma concepção menos negativa do portunhol que se produz na sala de aula de espanhol, parto da discussão proposta por Dufva, Suni, Aro e Salo $(2011$, 2012), que buscam compreender como as línguas são compreendidas nas salas de aula como objetos de ensino. Segundo as autoras, o ensino de línguas apresenta geralmente quatro características que podem ser associadas a uma concepção monolíngue do conceito de língua - (1) o conceito de língua nacional, (2) língua como uma gramática, (3) língua como forma e (4) língua como representação escrita.

De acordo com as autoras, a primeira característica - o conceito de língua nacional - está associada às ideologias de nacionalismo e, provavelmente, seja a forma mais comum de pensar o ensino de línguas. Nessa perspectiva monolíngue, o aluno aprende uma língua, ou seja, a língua nacional - por exemplo, o espanhol, o inglês, o francês. Língua, portanto, é uma entidade singular, um sistema essencialmente fechado, autônomo e diferente de outras línguas, atrelado a um território geográfico específico que possui uma língua comum, uma língua-padrão. A concepção de purismo linguístico, dessa forma, se torna o centro do conceito de língua nacional - as variedades marginalizadas e as línguas minoritárias, que integram o território-nação, são consideradas negativas e potencialmente problemáticas, influências que corrompem a "pureza" da língua-mãe. No caso do ensino de espanhol no Brasil, é preciso considerar também que o conceito de língua nacional está diretamente relacionado com a Espanha, como bem observa Zolin-Vesz (2013), o que promove, conforme o autor, para certa invisibilidade dos demais países do mundo hispânico.

A segunda característica - língua como uma gramática - está associada ao conceito de língua nacional e à concepção de que uma língua pode ser dominada por meio de um conjunto abstrato e descontextualizado de regras gramaticais. $\mathrm{O}$ ensino da gramática de uma língua oferece ao aprendiz, portanto, o consenso de como a língua deve ser usada e, principalmente, uma única norma atrelada a uma língua 
"pura". Dessa forma, a gramática é apresentada como o objetivo da aprendizagem de uma língua, na forma de regras gramaticais e itens lexicais que usam terminologia metalinguística para descrever a língua em termos de, por exemplo, verbos e adjetivos. Contudo, como lembram Dufva et al. $(2011,2012)$, conhecer uma regra gramatical, no sentido de que alguém pode produzir uma sentença gramatical, não é idêntico a repetir a formação dessa regra. Ou seja, o simples fato de o aprendiz conhecer a estrutura de determinado tempo verbal não significa que isso resultará na habilidade de usá-lo corretamente. Além disso, ainda segundo as autoras, nessa concepção, aprender está associado a um processo de adição, ou seja, as regras da gramática e o vocabulário de uma língua podem ser adicionados, em uma sucessão de estágios, até que a língua seja aprendida por inteiro, o processo de aquisição esteja completo e uma nova competência é ganha. Esse processo ancora, entre outros, o conceito de interlíngua.

A terceira característica - língua como forma -, interligada com as duas características anteriores, estabelece a primazia das formas e das estruturas linguísticas para a aprendizagem de línguas. Nessa perspectiva, sistemas linguísticos são separados de seus contextos sociais, de suas funções como ferramentas de interação, de seu potencial para a significação, de seu uso, o que, conforme as autoras, parece ser o mais importante para a maioria dos aprendizes. O foco no estudo do conhecimento formal das línguas, na visão das autoras, ignora a questão de como esse conhecimento é transformado em uso produtivo das línguas em suas formas oral e escrita, ou ainda, em usos social e culturalmente apropriados.

Por fim, a quarta característica da concepção monolíngue do conceito de língua se relaciona à primazia da representação escrita nas práticas de ensino das línguas. Desse modo, o conceito de língua nacional se combina com a ideia de sua gramática formal e descontextualizada presente na forma escrita. $\mathrm{O}$ aprendiz aprende uma língua, memorizando o conhecimento formal dessa língua (sua gramática) assentado em fontes impressas. Essa característica contribui para produzir, de acordo com Dufva et al. $(2011,2012)$, uma epistemologia monológica que, na sala de aula, resulta na política da resposta correta, da voz singular e da autoridade.

Em suma, a inter-relação entre essas quatro características do conceito monolíngue de língua alimenta a máxima de "uma língua, uma norma", apresentando línguas como códigos autônomos que devem ser mantidos em paralelo e que, de preferência, nunca se tocam. 


\section{POR UMA PEDAGOGIA TRANSLÍNGUE PARA O ENSINO DE ESPANHOL}

Em contraposição à concepção monolíngue do conceito de língua descortinada na seção anterior, Dufva et al. $(2011,2012)$ enfatizam a natureza variante e mutável das línguas, ou seja, sua heteroglossia, conceito bakhtiniano que, segundo as autoras, vem recorrentemente sendo usado para as discussões sobre diversidade linguística.

Nos escritos de Bakhtin, ainda palmilhando os passos das autoras, há dois tipos de estratificação linguística: por um lado, há a "diversidade intralingual", a estratificação interna presente em uma língua nacional que também envolve diferentes posições ideológicas. Por outro, há a "pluralidade de línguas", ou seja, a diversidade também pode ser observada pela presença de várias línguas e dialetos na comunidade a que pertencem. Dessa forma, o conceito bakhtiniano de heteroglossia sugere que mesmo as línguas nacionais são constituídas de diferentes usos social e funcionalmente estratificados, ou seja, as pessoas não aprendem "uma" língua, no sentido de um código unificado, mesmo em relação a sua língua materna, mas aprendem uma variedade de formas para compreender e usar os recursos linguísticos ao seu redor. Em nosso mundo contemporâneo, por meio da mídia, da propaganda, dos produtos e mercadorias comercializadas internacionalmente, lembram as autoras, mais do que nunca, isso enfeixa usos e elementos de "outras" línguas, o que mostra que as fronteiras entre línguas não são fixas, e diversos tipos de translíngua ocorrem - tanto na comunidade linguística quanto em contextos multiétnicos e mesmo na sala de aula.

O termo translíngua, conforme García, Flores e Woodley (2012), é uma tradução do conceito galês de trawsieithu, feita por Colin Baker, em 2001, de uma pedagogia bilíngue, proposta por Cen Williams, em que o insumo é dado em uma língua e a resposta é dada na outra língua. Desde então, a definição do termo tem sido expandida e usada para se referir ao uso bilíngue flexível no ensino e na aprendizagem. Nessa perspectiva, bilinguismo deixa de ser entendido como dois sistemas monolíticos separados por conjuntos de características específicas de cada um, mas como uma série de práticas linguísticas e sociais que estão embutidas em uma rede de relações sociais complexas (GARCÍA et al., 2012). Translíngua, portanto, é o processo pelo qual estudantes bilíngues e professores se engajam em complexas práticas discursivas a fim de "criar sentidos" em salas de aula essencialmente multilíngues (GARCÍA; SYLVAN, 2011). Nesse contexto, o termo translíngua, por um lado, responde aos complexos e multilíngues processos que encartam as práticas linguísticas das pessoas no mundo contemporâneo, pautado por fronteiras fluidas 
entre as línguas. Por outro, desafia a visão de que as línguas (nacionais) são autônomas e puras, conforme construída pelo pensamento ocidental e já discutida em outro passo. Translíngua, portanto, é o produto de uma "epistemologia de fronteira" (MOITA LOPES, 2008).

A concepção de epistemologia de fronteira, conforme proposta por Moita Lopes (2008), está pautada no que o semioticista Walter Mignolo chama de "pensamento nas margens ${ }^{3 \prime \prime}$, um modo de produzir conhecimento que constitui uma episteme das margens. Essa epistemologia, de acordo com Moita Lopes (2008), questiona os conceitos tanto de língua quanto de língua nacional, já debatidos no texto, pois "não coincide com o projeto de fazer uma língua corresponder a um Estado-nação e a seus limites territoriais: uma experiência que tem aumentado em um mundo híbrido de fronteiras porosas como o nosso" (MOITA LOPES, 2008, p. 323). Nesse andar, uma epistemologia de fronteira vai além do binômio periferia-centro. Como observa Moita Lopes (2008, p. 323), "margens são entre-lugares onde o que é crucial são as incertezas da fronteira e o que aí é vivido". Retomando Mignolo, Moita Lopes (2008) propõe que a tarefa de uma epistemologia de fronteira é "recriar ou reconstruir os designs globais por meio das histórias locais", prestigiando "o entrelaçamento de múltiplas histórias locais" (MOITA LOPES, 2008, p. 323).

A pedagogia translíngue, conforme proposta por García et al. (2012), se alimenta dessas discussões sobre uma epistemologia de fronteira. Segundo os autores, pensar em translíngua na sala de aula significa trabalhar no entremeio entre os designs globais dos Estados-nação e seus sistemas educacionais, que apregoam o conceito de língua como códigos autônomos que devem ser mantidos em paralelo e que nunca se tocam, e as histórias locais de aprendizes que usam línguas em um mundo contemporâneo cada vez mais pautado por fronteiras fluidas e porosas entre as línguas. A pedagogia translíngue, portanto, se refere à construção de práticas linguísticas flexíveis, híbridas, que estão nas margens, a fim de desenvolver novas compreensões e novas práticas linguísticas, entre elas as práticas linguísticas tidas como acadêmicas.

Nessa perspectiva, o repertório linguístico do aprendiz não é considerado "fechado". Ao contrário, está sujeito a mudanças e modificações, está "em movimento". A aprendizagem de línguas, portanto, envolve a concepção de "aprender movendo-se" 4" $^{\prime \prime}$ DUFVA et al., 2011, 2012), ou seja, como somos seres em movimento, as pessoas podem mudar sua localização, não apenas no sentido geográfico,

3 Tradução de Moita Lopes (2008, p. 323) para border tbinking.

4 Tradução minha, do termo learning by moving.aluno os produziu. 
mas também no sentido identitário, ao moverem-se entre diferentes espaços - de casa para a escola ou entre as fronteiras linguísticas do espanhol e do português, por exemplo. Portanto, se tanto as pessoas quanto os usos das línguas estão em movimento, ensinar línguas possui um caráter essencialmente multi e translíngue, no sentido de que os aprendizes assumem novas posições, incorporam valores novos e ajustam sua identidade de usuários de língua conforme os vários usos e línguas que encontram. Por isso, minha posição neste artigo é que o portunhol que se produz na sala de aula de espanhol não é uma interlíngua, no sentido já desfilado, mas uma translíngua. Ele abarca uma epistemologia de fronteira que, como apresentei acima, destrona tanto o conceito clássico de língua quanto o de língua nacional e, principalmente, a perspectiva monolíngue de ensino de línguas que esses conceitos trombeteiam. Pensar o portunhol como translíngua envolve considerar o movimento entre as fronteiras linguísticas do português e do espanhol, ou seja, envolve um "aprender movendo-se", uma vez que essas fronteiras linguísticas em sala de aula, exponencialmente, se tornam mais fluidas e porosas, maximizadas pela proximidade entre ambas as línguas.

Tomemos como exemplo duas produções textuais ${ }^{5}$ de um aluno aprendiz de espanhol, que possuem algumas construções linguísticas que foram consideradas erros pelo professor de espanhol. Como diria esse professor, é possível identificar a "interferência" do português na "tentativa" da construção em espanhol.

Texto 1

\section{EXPRESIÓN ESCRITA}

Escribe un pequeño texto, mínimo 8 y máximo 15 líneas, en español, describiendo tu habitación.

Vivo en una casa a la cerca del Shopping Pantanal. Tengo tres habitaciones, un salón del comedor, un baño, cocina y una garaje. Es muy pequeña con $80 \mathrm{~m} 2$. En el salón del comedor tiene lámpada y una bella ventana a la derecha de una mesa con sillas donde yo me desayuno todo los días. En una habitación, tiene una estanteria del libros que está delante de un sofá. La cocina tiene armários y una mesita. En mi habitación que yo duermo tiene una mesa de ordenador donde yo trabajo y una televisión.

Texto 2

¿Puedes imaginar cómo es un día normal en la vida de Bruno, el marido de Marta? Escríbelo.

5. Os textos estão transcritos como o aluno os produziu. Os textos já corrigidos pelo professor de espanhol estão anexos. 
Bruno se levanta las 7:30h cuando su mujer lo despierta. Él se ducha y se perfuma. Él desayuna pan, leche y café. Después, él se pone a leer el periódico. Él empieza a trabajar las 9:00h en una escuela de lengua. Bruno es un profesor de lengua y enseña Español para brasileños que viven en Madri.

Él almuerza en un restaurante cerca de su trabajo. Después, él se va a dormir una siestita.

Las 5:00, Bruno vuelva para su casa y baña su niño Hugo. Él ceña con su esposa Marta y charlan y ven la tele.

A qual língua pertencem essas construções? Ao português? Ao espanhol? Ou se trata apenas de uma "mistura" com o português, amarrada ao domínio insuficiente da língua espanhola, como parece acreditar o professor de espanhol diante das correções que faz nos textos? Trata-se da não progressão do aprendiz em direção ao domínio proficiente da língua espanhola? Por que não pensar que se trata de expressões translíngues, que se encontram na fronteira, no movimento que o aprendiz faz, como falante de língua portuguesa, em direção à "criação de sentidos" por meio da produção escrita? Não estariam os aprendizes, nesse movimento, assumindo novas posições, incorporando valores novos e ajustando sua identidade de usuários de línguas conforme os vários usos e línguas de que dispõem? Isso não compõe um mundo essencialmente heteroglóssico, multilíngue, como discuti em outro giro, cujas fronteiras entre as línguas se tornam cada vez mais porosas e fluidas?

Uma pedagogia translíngue para o ensino de línguas proporciona, portanto, construir uma sala de aula pautada na equidade entre os alunos, em que todos detêm oportunidades iguais para participar, já que o objetivo é criar sentidos. Em vez de "a resposta correta" e "a voz singular", múltiplas vozes, múltiplas línguas são convocadas para que o aluno desenvolva sua consciência multilíngue e, de conseguinte, a tolerância à diversidade linguística.

Para finalizar, algum leitor mais atento irá perceber, ao passar os olhos pelas referências abaixo, que o título deste artigo foi inspirado no trabalho de AssisPeterson (2008). Assim como a autora, ao entender que "podemos ser felizes em meio a anglicismos, pois eles fazem parte da paisagem brasileira, urdida no espaçotempo complexo da contemporaneidade, um espaço-tempo em que as fronteiras nacionais, em todas as suas dimensões, estão se desfazendo" (ASSIS-PETERSON, 2008, p. 338), acredito também que os professores de espanhol podem ser felizes em meio ao portunhol que se produz na sala de aula de espanhol. Como tentei apresentar neste artigo, as produções linguísticas, em portunhol, dos alunos fazem parte do movimento de construção de sentidos e de identidades, cujas fronteiras, em nosso mundo contemporâneo, se tornam cada vez mais fluentes e permeáveis. 


\section{AINDA UMA PALAVRA, QUE BEM PODERIA SER A MINHA...}

Como bien lo sabemos, el lenguaje siempre fluye y escapa al control de gobiernos, académicos y profesores, y cada hablante con su idiolecto, así como "cada maestro con su librito". Además de historia, literatura y lingüística, las lenguas son gesto, tono y contexto, y sin duda la movilidad y ductilidad del contacto entre español y portugués irán provocando sutilísimos cambios y variantes en un proceso imprevisible. ¿Y en nuestra loca carrera como profesores por eliminar las "contaminaciones", no estaremos atrapados en un efecto no ajeno a la globalización y los mercados: estabilizar un standard español y un standard portugués? ¿Y ese mar de posibilidades que es internet, no estará generando nuevos pidgin como lo fue el sabir, la lengua franca que perduró desde las Cruzadas hasta el siglo XIX, entre todos los marineros que partían del Mediterráneo uniendo todos los océanos? Comercio, contactos, el planeta como un maravilloso laboratorio de idiomas, procesos controvertidos y complejos de los que estamos percibiendo sólo algunos detalles (SATO, 2010, s/n).

\section{REFERÊNCIAS BIBLIOGRÁFICAS}

ASSIS-PETERSON, A. A. (2008). Como ser feliz no meio de anglicismos: processos transglóssicos e transculturais. Trabalbos em Linguística Aplicada, vol. 47, n. 2, pp. 323-340.

DUFVA, H.; SUNI, M.; ARO, M.; SALO, O. P. (2011). Languages as objects of learning: language learning as a case of multilingualism. Apples - Journal of Applied Language Studies, vol. 5, n. 1, pp. 109-124.

DUFVA, H.; SUNI, M.; ARO, M.; SALO, O. P. (2012). The changing concept of language. Disponível em < https://www.jyu.fi/hum/laitokset/kielet/henkilosto/hannele-dufva/ dufva_etal the changing_concept_of_language.pdf $>$ Acesso em 20 janeiro 2013.

GARCÍA, O.; SYLVAN, C. E. (2011). Pedagogies and practices in multilingual classrooms: singularities in pluralities. The Modern Language Journal, vol. 95, n. 3, pp. 385-400.

GARCÍA, O.; FLORES, N.; WOODLEY, H. H. (2012). Transgressing monolingualism and bilingual dualities: translanguaging pedagogies. In: YIAKOUMETTI, A. (ed.) Harnessing linguistic variation to improve education. Bern: Peter Lang, pp. 45-75.

LIPSKI, J. M. (2006). Too close for comfort? The genesis of "portuñol/portunhol". In: FACE, T. L.; KLEE, C. A. (eds.) Selected Proceedings of the sth Hispanic Linguistics Symposium. Somerville: Cascadilla Proceedings Project. Disponível em <http://www.lingref.com/cpp/hls/8/paper1251.pdf> Acesso em 20 janeiro 2013.

MOITA LOPES, L. P. (2008). Inglês e globalização em uma epistemologia de fronteira: ideologia linguística para tempos híbridos. D.E.L.T.A., vol. 24, n. 2, pp. 309-340.

MOTA, S. S. (2012). Portunhol - do domínio da oralidade à escrita - indícios de uma possível instrumentalização? In: STURZA, E. R.; FERNANDES, I. C. S.; IRALA, V. B. (orgs.) Português e espanbol: esboços, percepções e entremeios. Santa Maria: PPGLetras Editores, pp. 199-222. 
REIS, C. F. (2010). Os sentidos de portunbol e spanglish no espaço enunciativo da Internet: um estudo das relações de determinação e (des)legitimação. Dissertação (Mestrado em Linguística) - Instituto de Estudos da Linguagem, Universidade Estadual de Campinas, Campinas, 2010.

SATO, A. (2010). Portuñol como work in progress. Mejor dicho: portuñoles como work in progress. Disponível em <http://sitemason.vanderbilt.edu/files/ejSViw/Amalia\%20 $\underline{\text { Sato.docx }}>$ Acesso em 23 junho 2013.

ZOLIN-VESZ, F. (2013). A Espanha como o único lugar em que se fala a língua espanhola - a quem interessa essa crença? In: ZOLIN-VESZ, F. (org.) A (in) visibilidade da América Latina no ensino de espanbol. Campinas: Pontes, pp. 51-62. 


\section{Anexos}

Texto 1

\section{DXPRESIÓN ESCRITA}

Escribe un pequeño texlo, mímimo 8 y máximo 15 líneas, en español, describiendo tu habitación. (Valor 3,0)

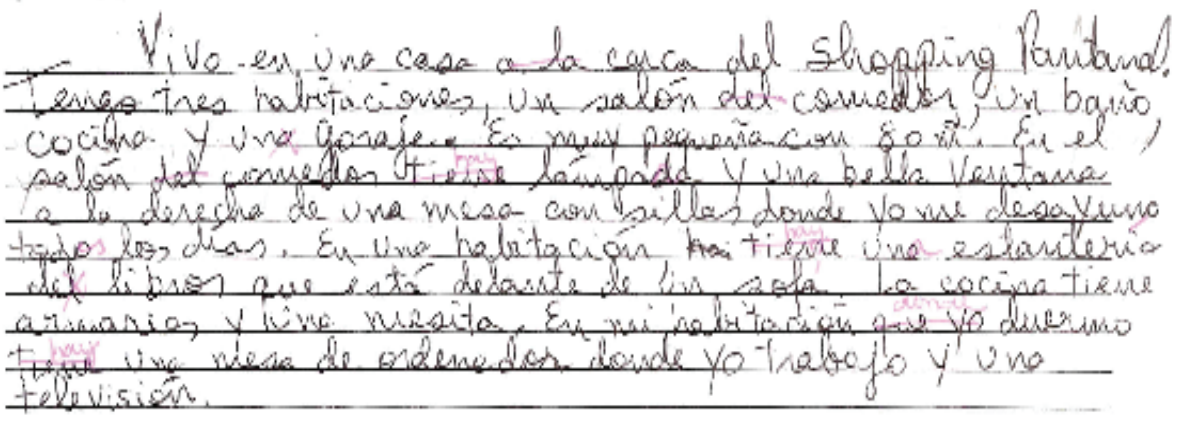

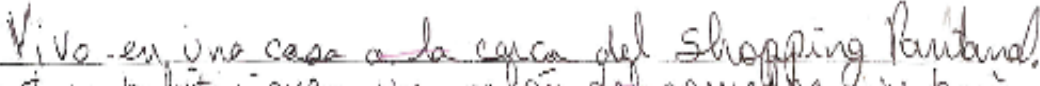

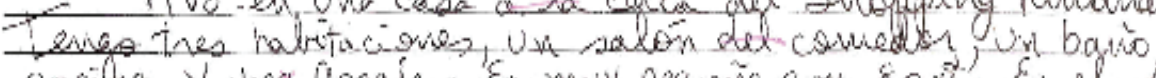

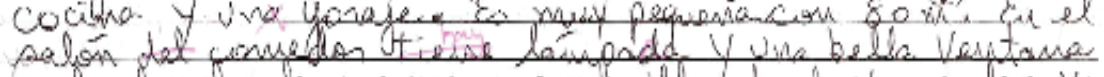

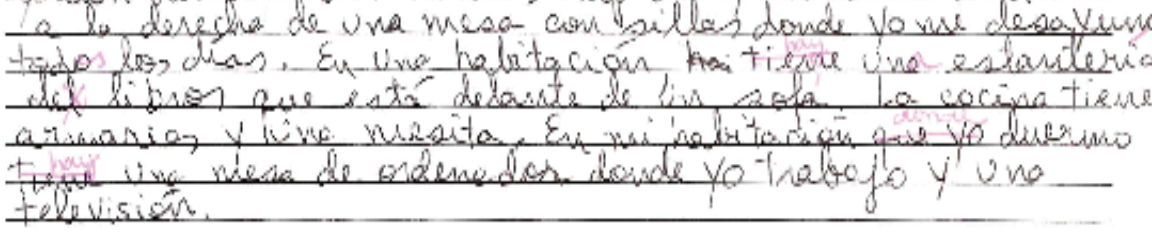

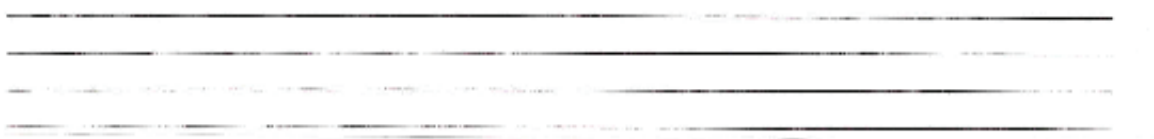


Texto 2

¿Pucxles imaginar ómo es un día nonrial en la vida de Brunte, el murido de Marta? Escribelo.

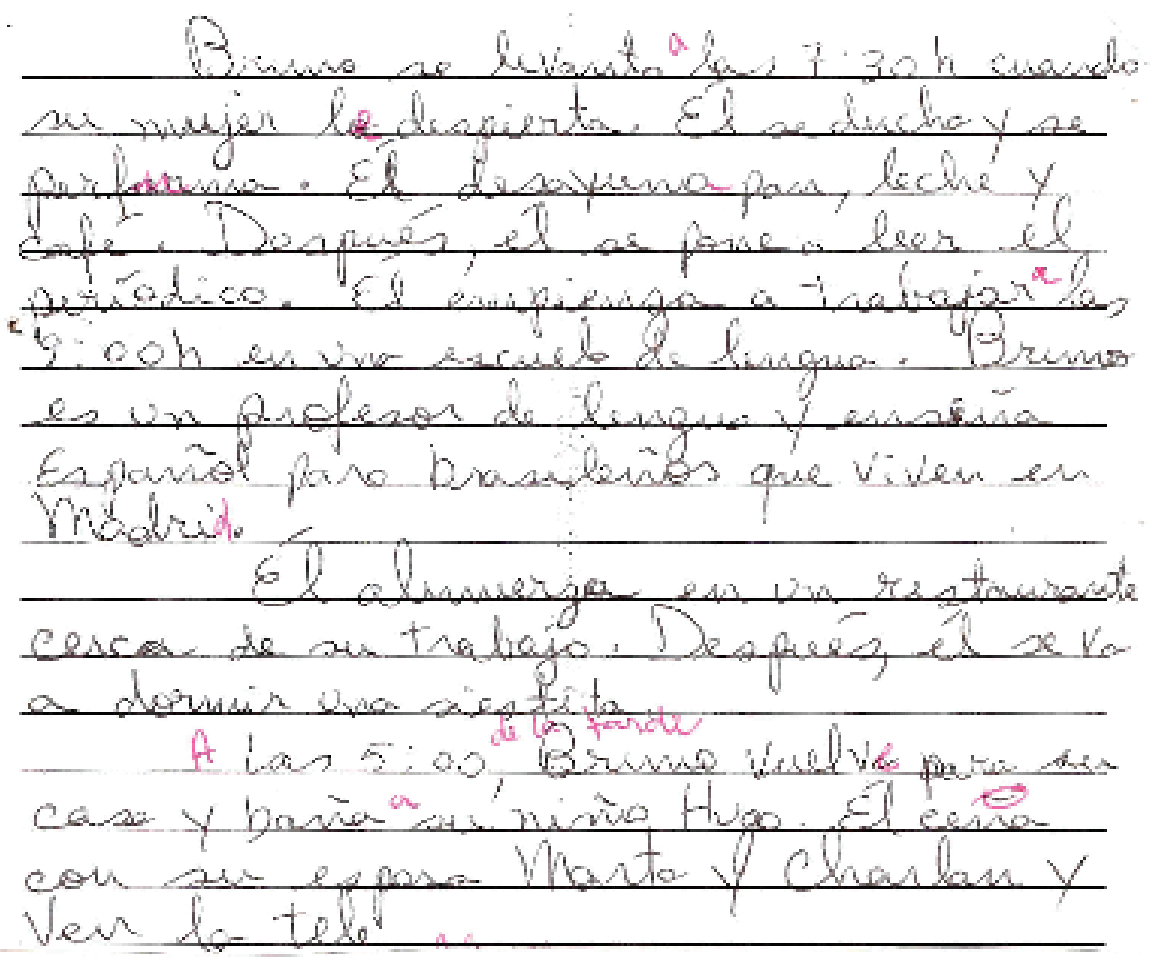

Recebido: $16 / 07 / 2013$

Aceito: $27 / 08 / 2014$ 